\title{
Ancillary Service Requirements Assessment Indices with the LFC in a Restructured Power Systems for RFB Unit by using Bacterial Foraging Optimization
}

\author{
ND. Sridhar
}

\begin{abstract}
This paper proposes the calculation methodology to leverage the System Support Service Request Valuation Indices (PSASRAI) facility of thetwo _Area Thermal Heat Intersected Power Network (TATRIPS) to highly restored environments. Both Indices display in the supporting demand of the Facility to improve the efficacy of the facility framework's physical activity. In the associated degree interconnected control system, the associated degree sudden strain hassle in any area triggers the frequency variance of the considerable variety of territories and in addition within the tie _line forces. To ensure nice quality, this should be updated to confirm age \&circulation of electrical power organizations.In addition to Integral (PI) sort controllers, there are broad uses in the dominant problems of Load Frequency Management (LFC). Consequently, the establishment of the PI management benefits for the restored control system is obtained using the calculation of microorganism hunt optimization (BFO). These regulatorsareexistent to accomplish a quicker reclamation periodwithinyield reactions of the framework. Conjointly vitality reposition is associate degree seductiveoption to embrace within the interest facet administration execution, thereforechemical reaction Flow Batteries (RFB) unit isprofitablywont to satisfy the headwould like and upgraded power gridsupportive Service demand Assessment Indices.
\end{abstract}

Keywords:Load, Redox Flow Batteries, Proportional plus C omprehensive Controller, Frequency Control, Power Systems Requirement Valuation Indices.

\section{INTRODUCTION}

These are aim from the Loaded Frequency Management intochangeprincipal frequency control, take the frequency to its par significance\&eliminate special tie-line powers flow among the adjacent management space. Thisworking role from an affecting mechanism variations over period, enabling the structure to encounter variations in marginal frequency \& planned power connectionsthrough alternative areas, which could produce unwanted effects. Two troubling variables, system frequencies \& tie-line powers exchange, bear variations owing from the disruptive load disruptions that constantly disrupt an impact network's traditional operation. In recent decades, numerous researchers have planned and studied a number of ways of controlling LFC power systems [1].

Flow frequency \& tie-line power interchange square variations subjective along true mixtures to a factor called space management fault (ACE).

Revised Manuscript Received on December 30, 2019.

* Correspondence Author

Dr. ND. Sridhar, Assoc. Professor, Dept. of Electrical Engineering, Annamalai University, Chidambaram, Tamil Nadu.

Email: sridarnd1@gmail.com

(C) The Authors. Published by Blue Eyes Intelligence Engineering and Sciences Publication (BEIESP). This is an open access article under the CC BY-NC-ND license (http://creativecommons.org/licenses/by-nc$\underline{\mathrm{nd} / 4.0 /)}$
In surrounding context, from generally agrees in the primary steps into the distinguish between power group\& transmission \&delivery firms, thereby placing entire generation on a constant balance because of the independent power producer (IPP) [2, 3]. An explosive load disturbance in someareabases frequency abnormality of total zones and jointly within the tie _line controls in Associate in interconnected nursing facilities. It needs to be corrected to ensure smart performance in order to confirm the generation \&circulation of electrical powercorporations.This dismiss be done via optimally standardizing the gains from the Load-Frequency regulator. Over the past six decades, numerous spatial Load-Frequency Control (LFC) experiments have been carried out for interconnected power systems in deregulated environments[4-7]. These studies aim to adapt the traditional LFC model to include consideration of the complexity impact of bilateral contracts and enhance the active and temporaryreaction of framework in different workingcircumstances.

Supplementaryfacilities can demarcated as a collection of actions performed through generators, shoppers \&network facilitybenefactors\&correspondinginframework operator who must be compelled to maintain adequate supply and quality of supply to justify the idea of commercial goods such as operation in major industrial markets[8]. (i) Short energy balance and facility size in conjunction with the introduction of commodity exchange. These will be tagged as the Frequency Management Adjunct Services (FCAS). (ii) Related to other than frequency bid reliability aspects (mainly voltage and system safety). These are tagged as leadership of the Network Adjunct Services (NCAS) (iii) Restored or Network restarted after large black-outs. It is branded with Systems Restoration Adjunct Service (SRAS). During in the paper, specific methodologyaimed atdual-zone thermal heating up interrelated facilities (TATRIPS) were implemented in the computing facilities adjunct Service Request Assessment Indices (PSASRAI)in systems unnecessarily restructured. With the various PSASRAIs such as possible Valuation Indices (FAI) \&CompleteValuation Indices (CAI), it provides the correctiveproceduresnear be occupied such as the inclusion of extra spinning reserves, the introduction of active smart controls, the shedding of loads etc.With the black units start square calculation of the best interest in the early stages of plant reconstruction as a result of producing power for the auxiliary thermal system while the capacity does not start black. Under this situation, a traditional frequency regulation, i.e. because of its slow response, a governor may not now be ready to complete abrupt load changes.

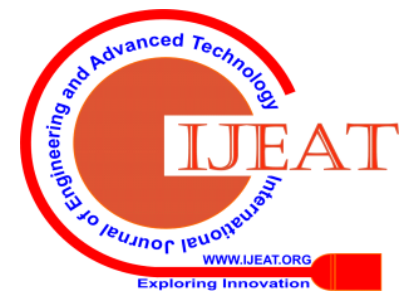




\section{Ancillary Service Requirements Assessment Indices with the LFC in a Restructured Power Systems for RFB Unit by using Bacterial Foraging Optimization}

Therefore, the damping of the major mechanical device oscillations must be effectively administered in a lay-space mode within the restructured facility. Furthermore, the coordination's management i/pconstraint muststay monitored \& remedial measures to beat the square excursion management input deviation measure appear to be additional to defend the structureearlier it arrivesanreservefunctioningmanner. Therefore, careful consideration is paid towardthe actions of systemconstraints, management equipment equally they influence power \&control of frequencies. A robust rapidresponse power supply such as oxide-reduction movement batteries (RFB) requires a variedassortment of submissions such as localized power conservation to complete abrupt load changes. The RFB has an active short-term overload quality and economic response features within the specific[12-14]. During this research, the BFO concept is used in an unnecessarily restructured process with and without an RFB unit to optimize the LFC PI gains from a two-area thermal heat up interconnected facility (TATRIPS). Numerous case studies examined directly square measure to create PSASRAI, Possible Index of Assessment (FAI) and Complete Index of Assessment (CAI) which square measure ready to predict traditional mode of operation, emergency mode and mode of capability restoration.

MODELING A DOUBLE-ZONE THERMAL REHEAT INTERRELATED POWER STRUCTURE (TATRIPS)

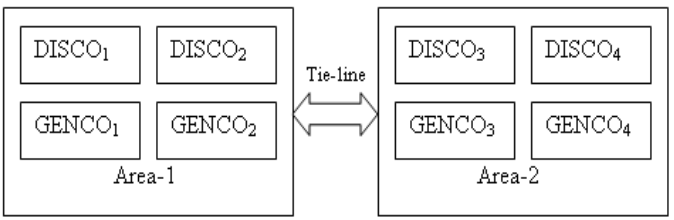

Fig.1 Two-area process graphicillustration in restructured environment

The framework for deregulated power includes DISCOs, GENCOs \& Transmission Companies (TRANSCOs) and Self-governingScheme Operator (ISO). GENCOs who self-control fight to sell the power they produce in a free market. For the most part, the retail client will purchase from the neighborhood circulation organization for quite a while, and DISCOs have been assigned to transport organizations.TRANSCOs have been allocated to the elements that will wheel this energy between GENCOs \& DISCOs. Despite the fact that providing different functionalities for GENCOs, TRANSCOs \& DISCOs is adroitly spotless, there would still be organizations with joint or halfway accountabilities The LFC has to consider various forms of potential exchanges in a deregulated energy system, such as PoolCo-based exchanges, cooperative exchanges, and a mixture of these two. [15].

A dance hall will contract with a GENCO alone to use the facility in the new situation, and such transactions will be produced under ISO supervision. In concept from the "DISCO Participation Matrix" (DPM) to be used into clarify the contract picture, which mostly provides data on the dance hall's participation in the GENCO contract. In DPM, the quantity set of rows is up to the quantity of GENCOs, so the number of columns in the process depends on the quantity of DISCOs. Let GENCO 1 be in space one, GENCO 2, DISCO 1, dance hall two \& GENCO 3, GENCO 4, DISCO 3, dance hall four be in space two as shown in figure one. The correct DPM is as follows [4]

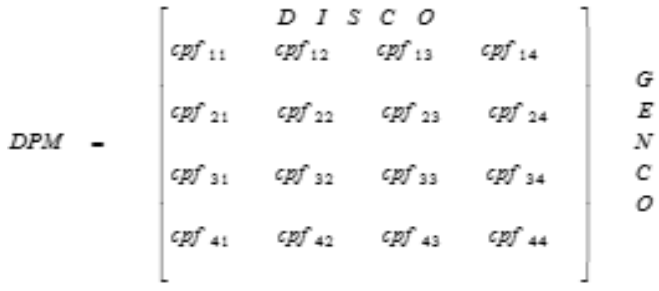

Where cpf stands for "Contract Participation Factor" \& is like indications containing information that the GENCO must follow the load requested by the dance palace.

$$
\begin{aligned}
& \Delta P_{\text {tie1-2, scheduled }}=\sum_{i=1}^{2} \sum_{j=3}^{4} c p f_{i j} \Delta P_{L j}-\sum_{i=3}^{4} \sum_{j=1}^{2} c p f_{i j} \Delta P_{L j} \\
& \Delta P_{\text {tie1-2, actual }}=\left(2 \pi T_{12} / s\right)\left(\Delta F_{1}-\Delta F_{2}\right)
\end{aligned}
$$

And at any given time, the tie-line power error is outlined as

$$
\Delta P_{\text {tiel-2, error }}=\Delta P_{\text {tiel-2 actual }}-\Delta P_{\text {tiel-2 scheáled }}
$$

The error signal is used to generate the respective ACE signals as in the traditional scenario

$$
\begin{aligned}
& A C E_{1}=\beta_{1} \Delta F_{1}+\Delta P_{\text {tie } 1-2, \text { error }} \\
& A C E_{2}=\beta_{2} \Delta F_{2}+\Delta P_{\text {tie 2-1, error }}
\end{aligned}
$$

For two area system as shown in Fig.1, the contracted power supplied by $\mathrm{i}^{\text {th }}$ GENCO is given as

$$
\begin{aligned}
& \Delta P g_{i}=\sum_{j=1}^{D I S C O=4} c P f_{i j} \Delta P L_{j} \\
& \text { Also note that } \\
& \Delta P L_{1, L O C}=\Delta P L_{1}+\Delta P L_{2} \& \\
& \Delta P L_{2, L O C}=\Delta P L_{3}+\Delta P L_{4} .
\end{aligned}
$$

In planned LFC enactment, shortened capacity is fed to GENCO set-points through the DPM matrix. Specific hundreds have an effect through the input of capacity blocks on system dynamics.

Any match between real and shrunken demands may consequence in frequency abnormalities that may result in LFC re-dispatching GENCOs in line with ACE participation factors, i.e. apf11, apf12, apf21 and apf22. An example of the minimal design of the interconnected space installation could also be shown in the state house (16)

$$
\begin{aligned}
& \dot{x}=\mathrm{A} x+\mathrm{B} u+\Gamma d \\
& y=C x
\end{aligned}
$$

Where $\mathrm{A}$ in the framework matrix, $\mathrm{B}$ in the o/pcirculation matrix, $\mathrm{x}$ is the disturbance distribution matrix, $\mathrm{C}$ in the command origin circulation matrix, $\mathrm{X}$ isstate-run vectors, \& $\mathrm{d}$ into load shift disruption vectors. 


\section{REDOX FLOW BATTERIES MATHEMATICAL MODELING}

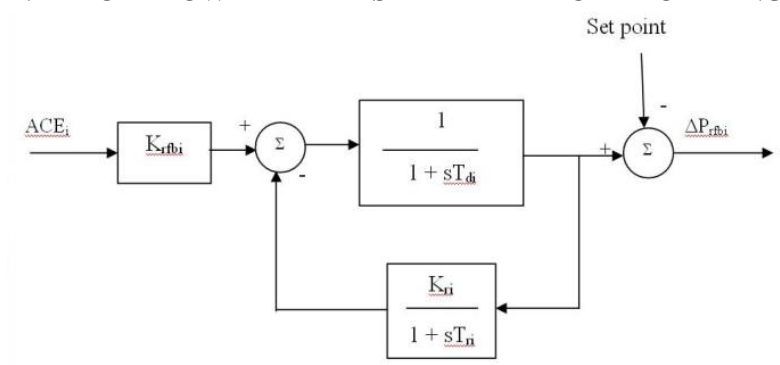

Figure. 2 Redox Flows Battery Structure models

Electrochemical cell flow devices, also known as batteries for chemical reaction flow, transform voltage into chemical P.E. By proposing a chemical reversible response between two liquid solutions. Unlike conventional batteries, chemical reaction flow cells store energy within resolutions. Consequently, the capacity \&vitalityassessmentsstay independent, throughloading capacity calculated via amount of solution recycled\& therefore power assessmentresolutethroughdynamic room in the cell chimney. In chemical reaction Flows Battery were incorporation into grid to mitigate in the associated problems of load frequency device in order to confirmbetter power proficiency.Flow Batteries ' chemical reaction is accomplished of confirming anactualfirmreaction\& checking is therefore not taking place due to a delay in response. Fig. 2 shows an example of the RFB unit diagram. The Error domain control (ACE) can be recycledas command signal for RFB management.

\section{A).Redox Flows Battery Units \&Controls Design}

Redo Flows Battery (RFB) area unit management activities in terms of response rate, frequency fluctuations [7] found to be superior to the operation of the governor process. The RFB area units are modified to easily reduce the height of frequency abnormalitiesbeside the fulminate load adjustment, which is motivated to account for the steady state loss of frequency variations after the regional governor device unit. Fig.3 shows 2 space-connected grid management style linearized reduction model by RFB components. The RFB element is formally receiving constant KRFB as an energetic power supply to space one with time constant TRFB. Time constants TRFB's management style is believed to be null sec [7], then the system status formula as shown in Fig. 3 Will be

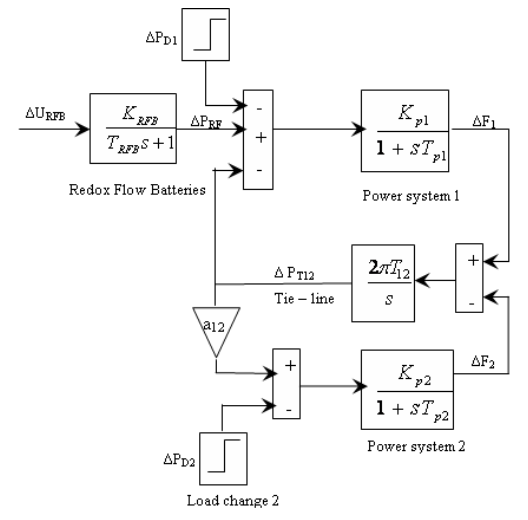

Figure. 3 Linearizeddecrease model \&mechanism design

$$
\left[\begin{array}{c}
\Delta F_{1} \\
\Delta \dot{P}_{T 12} \\
\Delta F_{2}
\end{array}\right]=\left[\begin{array}{ccc}
-\frac{1}{T_{p 1}} & -\frac{K_{p l}}{T_{p 1}} & 0 \\
2 \pi T_{12} & 0 & -2 \pi T_{12} \\
0 & \frac{a_{12} k_{p 2}}{T_{p 2}} & -\frac{1}{T_{p 2}}
\end{array}\right]\left[\begin{array}{l}
\Delta F_{1} \\
\Delta P_{R 2} \\
\Delta F_{2}
\end{array}\right]+\left[\begin{array}{l}
\frac{k_{p l}}{T_{p l}} \\
0 \\
0
\end{array}\right]\left[\Delta P_{R F A}\right]
$$

The development approach begins by reducing 2 space system into one space that reflects the Inertia center mode of the general system. For the corresponding one space module, the RFB controller is designed to reduce the inertia center frequency deviation. The analogous process results in being huge through the presumptuous synchronizing constant T12. From the equation of the state

$$
\begin{aligned}
& \Delta \dot{P}_{T 12} \operatorname{inEq}(9) \\
& \frac{\Delta \dot{\boldsymbol{P}}_{\boldsymbol{T} 12}}{2 \pi \boldsymbol{T}_{12}}=\Delta \boldsymbol{F}_{1}-\Delta \boldsymbol{F}_{2}
\end{aligned}
$$

Set the assessment of $T_{12}$ in Equation. (10) to be infinitudeyields $\Delta \mathrm{F} 1 \quad=\Delta \mathrm{F}_{2}$. Subsequent, throughreproducingformalequivalence of $\Delta \dot{F}_{1}$ and $\Delta \dot{F}_{2}$ by $\frac{T_{p 1}}{k_{p 1}} \quad$ and $\frac{T_{p 2}}{a_{12} k_{p 2}}$ respectively,

$\frac{T_{p 1}}{k_{p 1}} \Delta \dot{F}_{1}=-\frac{1}{k_{p 1}} \Delta F_{1}-\Delta P_{T 12}+\Delta P_{R F B}$

$\frac{T_{p 2}}{a_{12} k_{p 2}} \Delta \dot{F}_{2}=\frac{-1}{k_{p_{2}} a_{12}} \Delta F_{2}+\Delta P_{T 12}$

To Add Eq. (11) \& Eq.(12) \&expending the belowrelative $\Delta \mathrm{F}_{1}$ $=\Delta \mathrm{F}_{2}=\Delta \mathrm{F}$

$\Delta \dot{F}=\frac{\left(-\frac{1}{k_{p 1}}-\frac{1}{k_{p 2} a_{12}}\right)}{\left(\frac{T_{p 1}}{k_{p 1}}+\frac{T_{p 2}}{k_{p 2} a_{12}}\right)} \Delta F+\frac{1}{\left(\frac{T_{p 1}}{k_{p 1}}+\frac{T_{p 2}}{k_{p 2} a_{12}}\right)} \Delta P_{R F B}+C \Delta P_{D}$

Where $\Delta \mathrm{P}_{\mathrm{D}}$ is the load variation in this framework \& the regulate $\Delta \mathrm{P}_{\mathrm{RFB}}=-\mathrm{K}_{\mathrm{RFB}} \Delta \mathrm{F}$ is applied then.

$$
\Delta F=\frac{C}{s+A+K_{R F B} B} \Delta P_{D}
$$

Where $A=\left(-\frac{1}{k_{p 1}}-\frac{1}{k_{p 2} a_{12}}\right) /\left(\frac{T_{p 1}}{k_{p 1}}+\frac{T_{p 2}}{k_{p 2} a_{12}}\right)$

$$
B=\frac{1}{\left[\frac{T_{p 1}}{K_{p 1}}+\frac{T_{p 2}}{K_{p 2} a_{12}}\right]}
$$

Where $\mathrm{C}$ is the constant proportionality between frequency shift and load demand change. Since the control function of the RFB system. The percentage reduction of the final value can be given as a control specification after applying a step change. In Eq., (14) the definitivestandards with $\mathrm{K}_{\mathrm{RFB}}=0$ \&by way of $K_{R F B} \neq 0$ are $C / A \& C /\left(A+K_{R F B} B\right)$ respectively so the proportiondecline intocharacterized in

$$
C /\left(A+K_{\text {RFB }} B\right) /(C / A)=R / 100
$$




\section{Ancillary Service Requirements Assessment Indices with the LFC in a Restructured Power Systems for RFB Unit by using Bacterial Foraging Optimization}

Form given R, the device gain of RFB is designed as

$$
K_{R F B}=\frac{A}{B R}(100-R)
$$

These are linearly ideals of theinterrelates dual-parts reheated thermal powersstructure is tode-controls located is indicates in Figure.4 subsequentlyintegrating RFB units.

\section{DESIGNS OF DECENTRALIZED PI CONTROLLER}

The proportion Integral controllers gain value (Kpi, KIi) are tuned supported the sinking time of the o/preaction of classificationexploitationmicroorganismhuntimprovement (BFO) procedure. The barred-circle systemimmovability of system with thelocalized PI controller is assessed exploitationsinking time in the framework o/preaction [17, 18]. it's determined that the structure whose o/preactionresolvesquickcan has minimum sinking timesprimarily base criterion [19] and might is expressed as to

$$
\begin{gathered}
F\left(K_{p}, K_{i}\right)=\min \left(\zeta_{s i}\right)(17) \\
U_{1}=-K_{p} A C E_{1}-K_{I} \int A C E_{1} d t \\
U_{2}=-K_{p} A C E_{2}-K_{I} \int A C E_{2} d t(19)
\end{gathered}
$$

Where, $\zeta_{s i}=$ resolving time in the frequenciesabnormality of the ithspacebelowdisruption. The comparativedifficulty of this organizercould be eminentmethod just before the zero steady state _error inside frequency ofthe network. For thisenhanced gains value in the enactment tothe structures are analyzed\&numerous PSRAI area unit computed

\section{BACTERIAL FORAGING OPTIMIZATION TECHNIQUE}

Passion [9, 10] inspired by normal assortment, which seeks to eradicate animals with bad searching approaches and favors individuals with active foraging strategies, has applied the BFO technique. The foraging method is controlled by four procedures, namely chemo taxis, swarming, duplicate\& removal \&diffusion. In move into pre-defined directions, the bacterium is said to be swimming, \& tumbling in it started moves in a completely distinct directions. It is represent a drop, a random direction unit's length is generated. Let, " $\mathrm{j}$ " is the chemotactic step index, " $\mathrm{k}$ " is the step of reproduction and "l" is the scattering occurrence of elimination. Ith bacteria location at jth chemotactic stage kth reproduction step and lth removal dispersal activity. The bacteria's place in the next chemical phase after a tumbling

$$
\theta^{i}(j+1, k, l)=\theta^{i}(j, \quad k, l)+C(i) \phi(j)
$$

It is a bacteria's healthy improves after that crash, form the given steps into the bacteria's was continues to the swims into the same directions have deteriorated. Bacteria's exhibit swarm performance, i.e. strong bacteria attempt to theinterest other bacteria so that they get together more easily at the appropriate place (solution point). The effects of the swarming[10] is to congregate into the bacteria.

$$
\begin{aligned}
J_{c c}(\theta, P(j, k, l)) & =\sum_{i=1}^{S} J^{i} c c\left(\theta, \theta^{i}(j . k . l)\right) \\
& =\sum_{i=1}^{S}\left[-d_{\text {attract }} \exp \left(-\omega_{\text {attract }}\right) \sum_{m=1}^{p}\left(\theta^{m}-\theta_{m}^{i}\right)^{2}\right] \\
& +\sum_{i=1}^{S}\left[-h_{\text {repelent }} \exp \left(-w_{\text {repelent }}\right) \sum_{m=1}^{p}\left(\theta^{m}-\theta_{m}^{i}\right)^{2}\right]
\end{aligned}
$$

Members of the population with sufficient nutrients that replicate in the copy part and thus the least healthy microorganism may die. The improves residents exchanges unhealthy microorganisms that are removed by their lesser hunting abilities. It makes the population of microorganisms within the process of evolution stable. During this section, a bright unforeseen event can turn evolution into a contemporary setting and cause elimination and/or dispersion. Elimination and dispersion helps to reduce stagnation behavior, i.e. to be cornered for the benefit of an early response associate or an optimal neighborhood. The urged proportional and integral gain (KPi, KIi) programming technique $I=1,2$ ) allows the bacteria to require all doable values within the vary and minimizes the target activity represented by relative atomic mass Eqn. (17).

\section{SIMULATION RESULTS AND OBSERVATIONS}

The study's thought-about two-area thermal heat interconnected system consists of 2 GENCOs and 2 DISCOs in each room. In Appendix, the nominal parameters are given. Mistreatment of the frequency differences of management areas and tie-line power shifts is obtained the best resolution for the target output (17). RFB (KRFB) gain prices are calculated by relative atomic mass mistreatment (16) for the given velocity constant $(\mathrm{R})$ value. The RFB gain price is found to be KRFB = zero.67 The gains of the Proportional and Integral Manager (Kp Ki) are tuned to the BFO formula by optimizing the control input solutions for the assorted case studies as shown in Tables 1 and 2. 


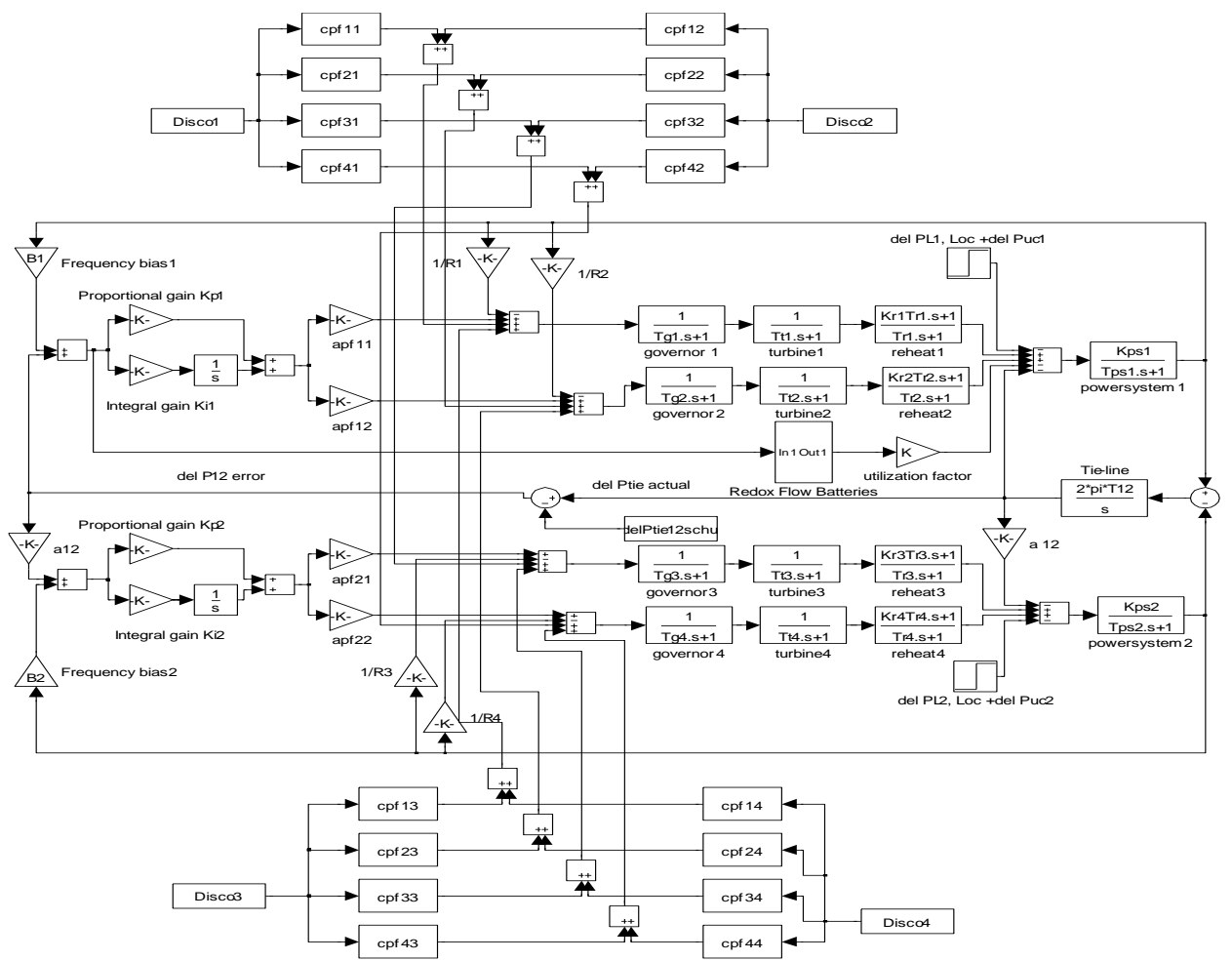

Fig. 4 Simulink ideal of a Dual- Part Thermal Reheat Interrelated Power System (TATRIPS) in rearranged environment with RFB unit

In this result is obtains in the programming of Matlab 7.01\& 100 emphases is choose to intermingle the arrangement using to the calculation ofBFO. Such PI controllers were modified into redesigned Two the Areas Thermal Re-heat Inter connected Power System within RFB system thinking about various limit uses $K=0,0.25$, $0.5,0.75,1.0 \&$ dissimilar types of the exchanges. These are related recurrence deviation ibf, tie-line divergence on controlling inputs deviation ibpc is a acquired as shown in Figs 5 and 6 for time. Results of reproduction show thanout the proposes PI controllers to the reconstructed control systems composed of RFB unit substantially lowers in the top or over or shoot or under-shoot of the recurrent deviation is the tie-line power deviation and further decreases to the controlling inputs prerequisites \& the settling time in the yield reactions is too significantly reduce. Increasingly more thanPower System, Ancillary Service Requirement Assessment Indices to be precise, Feasible AssessmentsIndices (FAI) while the systems operates into typical conditions within the two unit into operations onComplete Assessments Indices (CAI) as acquired as spoken of at least single units out-age in thesome area.

\section{A. Feasible Restoration Indices}

Scenarios 1: Poolco base transactions

Case 1:There are two thermal reheat systems in the TATRIPS considering both regions. Consider a case in which GENCOs are equally involved in LFC for Poolcobased transactions in each region. For Poolco-dependent transactions: load shift only occurs to the area 1 . It is denoteso as to the loads are provided one \&only between DISCO 1 and DISCO 2. Permit the costs for this load specifications to an 0.1for each MW to each of the circuit, that is. $\mathrm{PL} 1=0.1$ per $\mathrm{MW}, \mathrm{PL} 2=0.1$ per $\mathrm{MW}, \mathrm{PL} 3=$
0.0.0.0. DISCO contribution Matrices (DPM) with reference to $\mathrm{Eq}(1)$ is treated as [1-4].

$$
D P M=\left[\begin{array}{lcll}
0.5 & 0.5 & 0 & 0 \\
0.5 & 0.5 & 0 & 0 \\
0 & 0 & 0 & 0 \\
0 & 0 & 0 & 0
\end{array}\right]
$$

DISCO 1 and DISCO two need mathematically fromregional GENCOs, i.e. GENCO 1 and GENCO 2. so, $\operatorname{cpf} 11=\operatorname{cpf} 12=$ 0.5 and cpf21 $=0.5$. As shown in Figure 5, all areas ' frequencies deviation (UF), tie-line power deviations (UFP) into output specification deviations (UFPc) regulate deviations. Figure 5(d) and (e) evaluates in the corresponded FAI to following.

Steps 6.1 InFeasible Assessments Indexes $1\left(\varepsilon_{1}\right)$ are obtain in the ratiosamongthe settlingpoint in the controlling inputs deviated $\Delta P_{c 1}\left(\varsigma_{s 1}\right)$ responses into area one \&power system time constants $\left(T_{p 1}\right)$ of the area 1

$$
F R I_{1}=\frac{\Delta P_{c 1}\left(\varsigma_{s 1}\right)}{T_{p 1}}
$$

Steps 6.2 These Feasible Assessment Index $2\left(\varepsilon_{2}\right)$ be derives for the ratio intothe controls output variance settling time $\Delta P_{c 2}\left(\varsigma_{s 2}\right)$ responses of the areas $2 \&$ power systems time constants $\left(T_{p 2}\right)$ of area 2

$$
F R I_{2}=\frac{\Delta P_{c 2}\left(\varsigma_{s 2}\right)}{T_{p 2}}
$$




\section{Ancillary Service Requirements Assessment Indices with the LFC in a Restructured Power Systems for RFB Unit by using Bacterial Foraging Optimization}

Steps 6.3 The Feasible Assessments Index $3\left(\varepsilon_{3}\right)$ to peak values in the controls output variance is obtained $\Delta P_{c 1}\left(\varsigma_{p}\right)$ responses of the area (1) within respected in the final values $\Delta P_{c 1}\left(\varsigma_{s}\right)$

$$
F R I_{3}=\Delta P_{c 1}\left(\varsigma_{p}\right)-\Delta P_{c 1}\left(\varsigma_{s}\right)
$$

Step 6.4 The Feasible Assessment Index $4\left(\varepsilon_{4}\right)$ The total value is to control output variance is obtained

$\Delta \boldsymbol{P}_{c 2}\left(\varsigma_{p}\right)$ Responses of the areas 1 within respects in the final values $\Delta P_{c 2}\left(\varsigma_{s}\right)$

$$
F R I_{4}=\Delta P_{c 2}\left(\varsigma_{p}\right)-\Delta P_{c 2}\left(\varsigma_{s}\right)
$$

Cases(2): The situations is totoo refers to as an TATRIPSbased Poolco transaction in which GENCOs do not participate equally in each region and load demand in area 1is lower than GENCO and load demand shifts occur simply into areas 1 . These are reflected into the DPM matrix column entries and in the maximum columns entry are more than unity.

Case 3: A DISCO can infringe a contract by demanding more power than the contract specified and by not contracting any of the GENCOs with this excess power. GENCOs must supply this subcontracted energy to DISCO in the same region. It is recognized as the area's regional load but not as the requirement for the deal. Regard as scenarios- 1 within an shift so as to requires 0.1 p.u MW in the overload powers that is 0 .

Case 4: The cases is to similarly to the modification of Situation 2 that DISCO 3 requires on excess powers of the 0.1 p.u MW that is., sometimesPuc, 2=0.1 p.u MW \& sometimesPuc, 1=0 p.u MW. Cases 5: The case, it similarly to the Case 2 for a switch that DISCO 1 \&DISCO 3 need an excess energy of 0.1 p.u MW, i.e. 1=0.1 p.u MW and 2=0.1 p.u MW respectively.

Scenarios 2: Bi-lateral transactions

Cases 6: In the DISCOs contain agreements within the GENCO's \& the follows DISCO Participations Matrices (DPM) are listed here. [4].

$D P M=\left[\begin{array}{cccc}0.4 & 0.25 & 0.2 & 0.4 \\ 0.3 & 0.15 & 0.1 & 0.2 \\ 0.1 & 0.4 & 0.3 & 0.25 \\ 0.2 & 0.2 & 0.4 & 0.15\end{array}\right]$

In cases, GENCO DISCO 1, DISCO 2, DISCO 3 \& DISCO 4 need 0.15 per MW, 0.05 per MW, 0.15 per MW \&0.05 per MW is defined between the cpf into the DPM matrix \&each GENCO participated into the LFC as a define to the follows ACE participations parameter apf11= apf12 $=0.5$ and apf21 $=$ apf22 $=0.5$. Fig displays a variety of responses. 6.

Case 7In this scenario, bilateral TATRIPS transactions are also considered with a change that GENCOs do not participate equally in LFC in each region into loadscommand is to a greater that GENCO intotogether regions. But the change in load demand is assumed to occur intotogether area into the number of the columns entry in a DPM matrices in a higher than the units.

Cases 8: Again, given into cases 7 than DISCO 1 requires 0.1 p.u MW inthe overload powers, that is. 0.1 p.u. $\mathrm{MW}$ and $=0.0$ p.u. MW, respectively. Case 9: In the case of a change close to case 7 which DISCO3 needs an overload power of 0.1 p.u. MW, that is., under Puc, 2=0.1 p.u. MW. Case 10: When, similar to case 7, DISCO 1 and DISCO 3 allow 0.1 per MW of the excess power, that is .,= 0.1 per $\mathrm{MW}=0.1$ per $\mathrm{MW}$, equal to 0.1 per MW, 2=0.1 per MW, respectively. For the 1 10 events,Feasible Assessment Indices or to calculates into tabulates on Table 4.

\section{B. ComprehensiveAssessments Indices}

Separately to the conventional operated situation in the TATRIPS few in alternative cases studied such as 1 units outage into on locality, outage of the 1 distributed generation in Unitika District DISCO1DISCO2DISCO3DISCO4 partial portion is considered on an individual basis. These are corresponding CAI is obtain as a following with the varied cases studies and assisted their maximum benefits.

Cases 11: To the TATRIPS, given so as to the DISCO's has a deal in the GENCO's, other than GENCO4 is in zone-2. These case, GENCO's DISCO 1, DISCO 2, DISCO 3\& DISCO 4 need 0.15 p.u MW, 0.05 p.u MW, 0.15 pu. MW and 0.05 pu. MW since specified into the DPM matrices by cpf (24). GENCO4= 0.0 p.u MW production. Cases 12: Considered into this cases, while in the same as Case 11 except DISCO 1 needs on excess powers of the 0.1 per MW, i.e. $=0.1$ per MW and= 0.0 per MW, respectively.

Table 1 Optimizes Controllers parameter in the TATRIPS

\begin{tabular}{|l|c|c|c|c|}
\hline \multirow{2}{*}{ TATRIPS } & \multicolumn{2}{|c|}{$\begin{array}{c}\text { Controls gains of the } \\
\text { AREA 1 }\end{array}$} & $\begin{array}{c}\text { Controls gains of the } \\
\text { AREA 2 }\end{array}$ \\
\cline { 2 - 5 } & $\mathrm{K}_{\mathrm{p} 1}$ & $\mathrm{~K}_{\mathrm{i} 1}$ & $\mathrm{~K}_{\mathrm{p} 2}$ & $\mathrm{~K}_{\mathrm{i} 2}$ \\
\hline Case 1 & 0.342 & 0.458 & 0.191 & 0.081 \\
\hline Case 2 & 0.384 & 0.368 & 0.212 & 0.096 \\
\hline Case 3 & 0.428 & 0.394 & 0.237 & 0.127 \\
\hline Case 4 & 0.397 & 0.422 & 0.243 & 0.133 \\
\hline Case 5 & 0.411 & 0.437 & 0.254 & 0.138 \\
\hline Case 6 & 0.317 & 0.512 & 0.122 & 0.195 \\
\hline Case 7 & 0.336 & 0.528 & 0.138 & 0.183 \\
\hline Case 8 & 0.342 & 0.565 & 0.219 & 0.172 \\
\hline Case 9 & 0.356 & 0.567 & 0.243 & 0.194 \\
\hline Case 10 & 0.364 & 0.572 & 0.275 & 0.186 \\
\hline Case 11 & 0.385 & 0.577 & 0.278 & 0.174 \\
\hline Case 12 & 0.402 & 0.585 & 0.278 & 0.204 \\
\hline Case 13 & 0.418 & 0.588 & 0.287 & 0.236 \\
\hline Case 14 & 0.463 & 0.592 & 0.298 & 0.242 \\
\hline
\end{tabular}

In total loads into a area $1=$ Loads inthe DISCO $1+$ Load of the DISCO $2=\Delta \mathrm{PL} 1+\Delta \mathrm{Puc} 1+\Delta \mathrm{PL} 2=0.15+0.1+0.05=0.3$ p.u MW. 
Ancillary Service Requirements Assessment Indices with the LFC in a Restructured Power Systems for RFB Unit by using Bacterial Foraging Optimization

Totally loads into a area 2= Load of DISCO 3+Load of DISCO $4=\Delta$ PL3 $+\Delta$ PL4 $=0.15+0.05=0.2$ p.u MW.Case 13:The scenarios are the both as to in Scenario 11, where DISCO 3

requires 0.1 p.u $\mathrm{MW}$ for excesspower, i.e.= 0.1 p.u MW. Total load in area $1=$ DISCO $1+$ Load of DISCO $2=\$$ PL3 + PL4 $=0.15+0.05=0.2$ p.u MW \& maximum insist into area $2=$ DISCO $3+$ Load of DISCO4 $=\$ P L 3+$ PL4 + \$Puc3 $=0.15+0.05+0.1=0.3$ p.uMW.Case 14: the scenario, which is similar to Scenario 11 with a change that DISCO 1 \&DISCO 3 require 0.1 p.u MW inthe excesspower that is., PUC $1=0.1$ p.u. MW and PUC $3=0.1$ p.u MW, respectively. Totally loaded into area $1=$ DISCO load $1+$ DISCO load 2=\$PL1+\$PL2=0.15+0.1 + 0.05 = 0.3 per $\mathrm{MW}$ and total load in area $2=$ DISCO load $4=\$ P L 3+$ $\$ P L 4=0.15+0.1+0.05=0.3$ per MW. In corresponds in Assessment Indices is refers to the Comprehensive Assessment Indices form Cases 11-14 using Eq (23 to 26) as shown in Table 5.

C).Power Systems Ancillary Services Requirements Assessment Indices (PSASRAI)

\section{i) Based on Settling Time}

If $\varepsilon_{1}, \varepsilon_{2}, \varepsilon_{5}, \varepsilon_{6} \geq 1$ Then the integral gain of each control area must be increased, creating a wide opening of the velocity changer valve. Thus the position of the velocity-changer only reaches on constant valuesat what timein the fault of frequency in it is reduces to the zero. If $1.0<\varepsilon_{1}, \varepsilon_{2}, \varepsilon_{5}, \varepsilon_{6} \leq 1.5$ then there is a need for more distributed generation requirement. Energystorage is an attractive option for the increasing in the implementation of demand side management by ensuring the power system's auxiliary services. If $\varepsilon_{1}, \varepsilon_{2}, \varepsilon_{5}, \varepsilon_{6} \geq 1.5$ then the system becomes fragile and the system becomes volatile, and blackouts can even result.

\section{ii) Based on peak undershoot}

If $0.15 \leq \varepsilon_{3}, \varepsilon_{4}, \varepsilon_{7}, \varepsilon_{8}<0.2$ EnergyStorage Systems (ESS) in the requires form LFC as the traditional loaded frequency controls can be no long is to be ables to a attenuated in the high frequencies oscillator among the late responses in the controller to unpredictable load variations. In addition to the kinetic energy of the generator rotors, a fast-acting energy storage device is recommended tc dampen the frequency oscillations..I $0.2 \leq \varepsilon_{3}, \varepsilon_{4}, \varepsilon_{7}, \varepsilon_{8}<0.3 \quad$ further transmissior generation requirements are then required or organizec control of Energy Storage Systems (ESS) in FCTS system: are needs to the boosts in the relatively stable power: systems into the LFC applications\&loadedcracking is tc always prefer.In $\varepsilon_{3}, \varepsilon_{4}, \varepsilon_{7}, \varepsilon_{8}>0.3$ The system then becomes weak and unreliable and may result in blackout.
Table 2 Optimized Controller parameters of the TATRIPS With RFB

\begin{tabular}{|l|c|c|c|c|}
\hline \multirow{2}{*}{ TATRIPS } & \multicolumn{2}{|c|}{$\begin{array}{c}\text { Controls gain of the } \\
\text { AREA 1 }\end{array}$} & \multicolumn{2}{c|}{$\begin{array}{c}\text { Controls gain of the } \\
\text { AREA 2 }\end{array}$} \\
\cline { 2 - 5 } & $\mathrm{K}_{\mathrm{p} 1}$ & $\mathrm{~K}_{\mathrm{i} 1}$ & $\mathrm{~K}_{\mathrm{p} 2}$ & $\mathrm{~K}_{\mathrm{i} 2}$ \\
\hline Case 1 & 0.342 & 0.458 & 0.191 & 0.081 \\
\hline Case 2 & 0.384 & 0.368 & 0.212 & 0.096 \\
\hline Case 3 & 0.428 & 0.394 & 0.237 & 0.127 \\
\hline Case 4 & 0.397 & 0.422 & 0.243 & 0.133 \\
\hline Case 5 & 0.411 & 0.437 & 0.254 & 0.138 \\
\hline Case 6 & 0.317 & 0.512 & 0.122 & 0.195 \\
\hline Case 7 & 0.336 & 0.528 & 0.138 & 0.183 \\
\hline Case 8 & 0.342 & 0.565 & 0.219 & 0.172 \\
\hline Case 9 & 0.356 & 0.567 & 0.243 & 0.194 \\
\hline Case 10 & 0.364 & 0.572 & 0.275 & 0.186 \\
\hline Case 11 & 0.385 & 0.577 & 0.278 & 0.174 \\
\hline Case 12 & 0.402 & 0.585 & 0.278 & 0.204 \\
\hline Case 13 & 0.418 & 0.588 & 0.287 & 0.236 \\
\hline Case 14 & 0.463 & 0.592 & 0.298 & 0.242 \\
\hline & & & & \\
\hline
\end{tabular}

Table 3 Comparison of the system dynamic performance for TPTRIPS

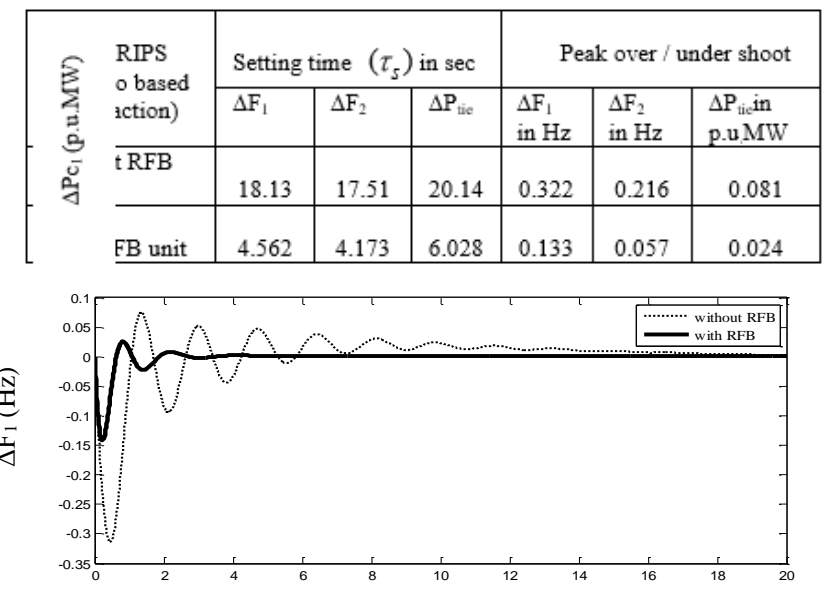

Fig. 5(a) $\Delta F_{1}$ (Hz) Vs Time ( Time (s)

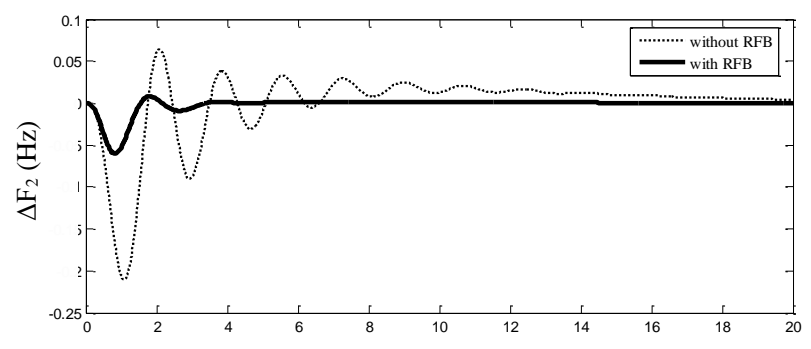

Fig.5 (b) $\Delta F_{2}(\mathbf{H z})$ Vs Time (s) Time (s)

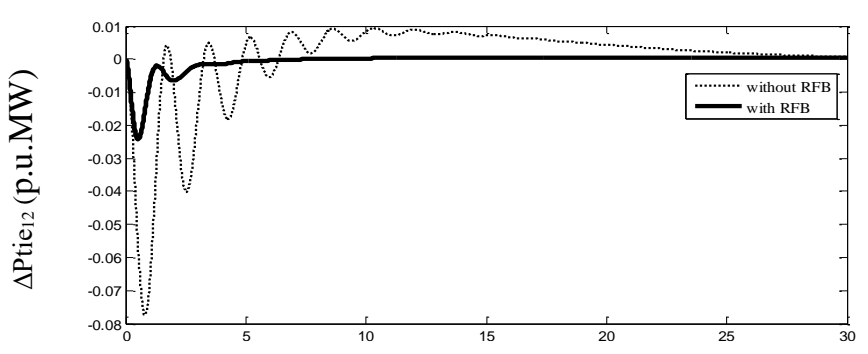

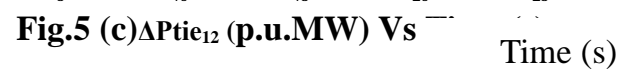


Ancillary Service Requirements Assessment Indices with the LFC in a Restructured Power Systems for RFB Unit by using Bacterial Foraging Optimization

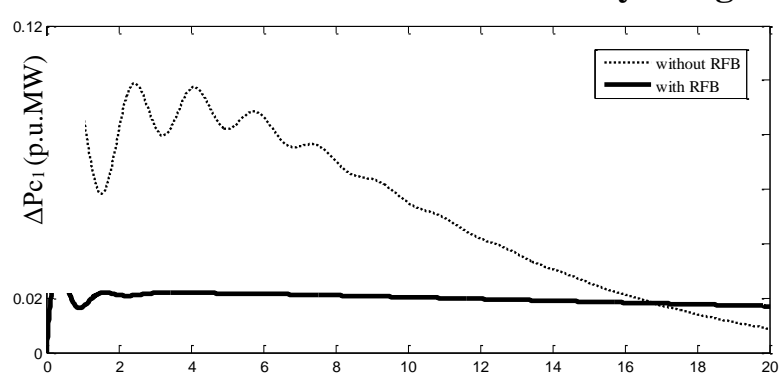

Fig.5 (d) $\Delta$ Pc1 (p.u.MW) Vs Time (s)

Time (s)

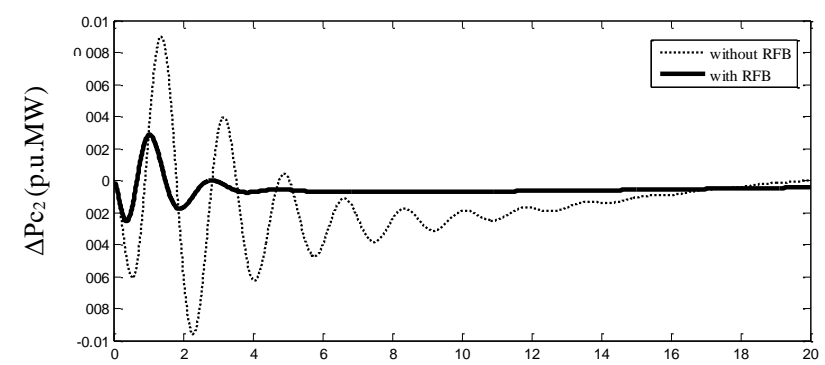

Fig.5 (e) $\Delta$ Pc2 (p.u.MW) Vs Time (s) Time (s)

Fig.5 Dynamic To Response In The Frequencıes vevıduvin,

Tie Line Power Deviation \&Managements Inputs

Deviation Form Tatrips Within The Restructures Scenario-1 (Poolcoprimarily Based Transactions)

\begin{tabular}{|l|l|l|l|l|l|l|l|l|l|l|}
\hline \multirow{2}{*}{ TATRIPS } & \multicolumn{3}{|c|}{ CAI based on control input deviations $\left(\Delta P_{c}\right)$} & \multicolumn{4}{|c|}{$\begin{array}{c}\text { CAI based on control input deviations } \\
\left(\Delta P_{c}\right)\end{array}$} \\
& $\varepsilon_{5}$ & $\varepsilon_{6}$ & $\varepsilon_{7}$ & $\varepsilon_{8}$ & $\int P_{\text {without }}$ & $\varepsilon_{5}$ & $\varepsilon_{6}$ & $\varepsilon_{7}$ & $\varepsilon_{8}$ & $\int P_{R F B}$ \\
& & & & & & & & & & \\
\hline Case 11 & 1.133 & 1.516 & 0.340 & 0.297 & 1.102 & 1.074 & 1.211 & 0.324 & 0.263 & 0.343 \\
\hline Case 12 & 1.523 & 1.523 & 0.381 & 0.342 & 3.193 & 1.141 & 1.297 & 0.330 & 0.311 & 0.411 \\
\hline Case 13 & 1.344 & 1.624 & 0.430 & 0.495 & 1.893 & 1.151 & 1.454 & 0.403 & 0.434 & 0.434 \\
\hline Case 14 & 1.626 & 1.734 & 0.457 & 0.511 & 3.270 & 1.347 & 1.533 & 0.418 & 0.501 & 0.441 \\
\hline
\end{tabular}

Table 4(a)FAIwith no \& with in RFB units $(K=1)$ for TATRIPS

\begin{tabular}{|c|c|c|c|c|c|c|c|c|c|c|}
\hline \multirow{2}{*}{$\begin{array}{l}\text { TATRIP } \\
\mathrm{S}\end{array}$} & \multicolumn{5}{|c|}{$\begin{array}{l}\text { Feasible Assessment Indices (FAI) based on } \\
\text { control input deviations }\left(\Delta P_{c}\right) \text { without } \\
\text { RFB unit }(\mathrm{K}=0)\end{array}$} & \multicolumn{5}{|c|}{$\begin{array}{c}\text { Feasible Assessment Indices (FAI) based on } \\
\text { control input deviations }\left(\Delta P_{c}\right) \text { with } \\
\text { RFB unit }(\mathrm{K}=1)\end{array}$} \\
\hline & $\varepsilon_{1}$ & $\varepsilon_{2}$ & $\varepsilon_{3}$ & $\varepsilon_{4}$ & $\int P_{\text {without }}$ & $\varepsilon_{1}$ & $\varepsilon_{2}$ & $\varepsilon_{3}$ & $\varepsilon_{4}$ & $P_{R F B}$ \\
\hline Case 1 & 0.974 & 0.887 & 0.134 & 0.028 & 1.057 & 0.814 & 0.724 & 0.098 & 0.009 & 0.527 \\
\hline Case 2 & 1.087 & 0.968 & 0.211 & 0.032 & 1.285 & 0.828 & 0.794 & 0.101 & 0.011 & 0.574 \\
\hline Case 3 & 1.325 & 1.026 & 0.298 & 0.044 & 3.263 & 0.837 & 0.904 & 0.127 & 0.013 & 0.583 \\
\hline Case 4 & 1.184 & 1.323 & 0.223 & 0.066 & 0.781 & 0.935 & 0.938 & 0.130 & 0.019 & 0.595 \\
\hline Case 5 & 1.460 & 1.376 & 0.301 & 0.084 & 3.948 & 1.041 & 1.081 & 0.234 & 0.048 & 0.453 \\
\hline Case 6 & 0.925 & 0.876 & 0.149 & 0.094 & 1.262 & 0.807 & 0.707 & 0.108 & 0.058 & 0.482 \\
\hline Case 7 & 1.125 & 0.916 & 0.217 & 0.097 & 1.453 & 0.905 & 0.900 & 0.148 & 0.076 & 0.525 \\
\hline Case 8 & 1.324 & 1.026 & 0.325 & 0.100 & 3.498 & 0.928 & 0.975 & 0.207 & 0.082 & 0.557 \\
\hline Case 9 & 1.233 & 1.328 & 0.214 & 0.183 & 1.032 & 0.865 & 1.053 & 0.171 & 0.148 & 0.607 \\
\hline Case 10 & 1.375 & 1.346 & 0.342 & 0.197 & 3.268 & 1.007 & 1.108 & 0.273 & 0.162 & 0.624 \\
\hline
\end{tabular}

Table 4(b)FAI with no \& with in RFB units $(\mathrm{K}=0.75)$ for TATRIPS 
Ancillary Service Requirements Assessment Indices with the LFC in a Restructured Power Systems for RFB Unit by using Bacterial Foraging Optimization

\begin{tabular}{|c|c|c|c|c|c|c|c|c|c|c|}
\hline \multirow{2}{*}{$\begin{array}{l}\text { TATRIP } \\
\mathrm{S}\end{array}$} & \multicolumn{5}{|c|}{$\begin{array}{l}\text { FAI based on control input deviations }\left(\Delta P_{c}\right) \\
\text { without RFB unit (utilization factor } \mathrm{K}=0 \text { ) }\end{array}$} & \multicolumn{5}{|c|}{$\begin{array}{l}\text { FAI based on control input deviations } \\
\qquad\left(\Delta P_{c}\right) \text { with RFB unit }(\mathrm{K}=0.75)\end{array}$} \\
\hline & $\varepsilon_{1}$ & $\varepsilon_{2}$ & $\varepsilon_{3}$ & $\varepsilon_{4}$ & $P_{\text {without }}$ & $\varepsilon_{1}$ & $\varepsilon_{2}$ & $\varepsilon_{3}$ & $\varepsilon_{4}$ & $P_{R F B}$ \\
\hline Case 1 & 0.974 & 0.887 & 0.134 & 0.028 & 1.067 & 0.874 & 0.801 & 0.104 & 0.010 & 0.458 \\
\hline Case 2 & 1.087 & 0.968 & 0.211 & 0.032 & 1.275 & 0.883 & 0.818 & 0.127 & 0.012 & 0.463 \\
\hline Case 3 & 1.325 & 1.026 & 0.298 & 0.044 & 3.253 & 0.886 & 0.924 & 0.136 & 0.019 & 0.526 \\
\hline Case 4 & 1.184 & 1.323 & 0.223 & 0.066 & 0.771 & 0.974 & 0.984 & 0.142 & 0.020 & 0.554 \\
\hline Case 5 & 1.460 & 1.376 & 0.301 & 0.084 & 3.938 & 1.208 & 1.103 & 0.254 & 0.052 & 0.447 \\
\hline Case 6 & 0.925 & 0.876 & 0.149 & 0.094 & 1.262 & 0.813 & 0.795 & 0.123 & 0.059 & 0.467 \\
\hline Case 7 & 1.125 & 0.916 & 0.217 & 0.097 & 1.454 & 0.939 & 0.891 & 0.163 & 0.074 & 0.528 \\
\hline Case 8 & 1.324 & 1.026 & 0.325 & 0.100 & 3.498 & 0.942 & 0.955 & 0.219 & 0.084 & 0.516 \\
\hline Case 9 & 1.233 & 1.328 & 0.214 & 0.183 & 1.037 & 0.945 & 1.044 & 0.187 & 0.154 & 0.554 \\
\hline Case 10 & 1.375 & 1.346 & 0.342 & 0.197 & 3.266 & 1.100 & 1.124 & 0.288 & 0.160 & 0.583 \\
\hline
\end{tabular}

Table 4(c) FAI with no \& with in RFB units (utilization factor $K=0.5$ ) Form TATRIPS

\begin{tabular}{|c|c|c|c|c|c|c|c|c|c|c|}
\hline \multirow[b]{2}{*}{$\begin{array}{l}\text { TATRIP } \\
\mathrm{S}\end{array}$} & \multicolumn{5}{|c|}{$\begin{array}{l}\text { FAI based on control input deviations }\left(\Delta P_{c}\right) \\
\text { without RFB unit }(\mathrm{K}=0)\end{array}$} & \multicolumn{5}{|c|}{$\begin{array}{l}\text { FAI based on control input deviations } \\
\left(\Delta P_{c}\right) \text { with RFB unit }(\mathrm{K}=0.5)\end{array}$} \\
\hline & $\varepsilon_{1}$ & $\varepsilon_{2}$ & $\varepsilon_{3}$ & $\varepsilon_{4}$ & $P_{\text {without }}$ & $\varepsilon_{1}$ & $\varepsilon_{2}$ & $\varepsilon_{3}$ & $\varepsilon_{4}$ & $P_{R F B}$ \\
\hline Case 1 & 0.974 & 0.887 & 0.134 & 0.028 & 1.067 & 0.874 & 0.784 & 0.107 & 0.011 & 0.430 \\
\hline Case 2 & 1.087 & 0.968 & 0.211 & 0.032 & 1.275 & 0.893 & 0.813 & 0.130 & 0.020 & 0.444 \\
\hline Case 3 & 1.325 & 1.026 & 0.298 & 0.044 & 3.253 & 0.905 & 0.923 & 0.143 & 0.022 & 0.511 \\
\hline Case 4 & 1.184 & 1.323 & 0.223 & 0.066 & 0.771 & 0.961 & 0.962 & 0.153 & 0.024 & 0.533 \\
\hline Case 5 & 1.460 & 1.376 & 0.301 & 0.084 & 3.938 & 1.183 & 1.103 & 0.267 & 0.057 & 0.424 \\
\hline Case 6 & 0.925 & 0.876 & 0.149 & 0.094 & 1.262 & 0.802 & 0.788 & 0.128 & 0.065 & 0.448 \\
\hline Case 7 & 1.125 & 0.916 & 0.217 & 0.097 & 1.454 & 0.935 & 0.882 & 0.170 & 0.080 & 0.483 \\
\hline Case 8 & 1.324 & 1.026 & 0.325 & 0.100 & 3.498 & 0.944 & 0.967 & 0.234 & 0.088 & 0.464 \\
\hline Case 9 & 1.233 & 1.328 & 0.214 & 0.183 & 1.037 & 0.933 & 1.118 & 0.183 & 0.163 & 0.533 \\
\hline Case 10 & 1.375 & 1.346 & 0.342 & 0.197 & 3.266 & 1.103 & 1.135 & 0.291 & 0.168 & 0.541 \\
\hline
\end{tabular}

Table 4(d)FAI with no \& with in RFB units $(K=0.25)$ for TATRIPS

\begin{tabular}{|c|c|c|c|c|c|c|c|c|c|c|}
\hline \multirow{2}{*}{$\begin{array}{l}\text { TATRIP } \\
\mathrm{S}\end{array}$} & \multicolumn{5}{|c|}{$\begin{array}{l}\text { FAI based on control input deviations }\left(\Delta P_{c}\right) \\
\text { without RFB unit }(\mathrm{K}=0)\end{array}$} & \multicolumn{5}{|c|}{$\begin{array}{l}\text { FAI based on control input deviations } \\
\left(\Delta P_{c}\right) \text { with RFB unit }(\mathrm{K}=0.25)\end{array}$} \\
\hline & $\varepsilon_{1}$ & $\varepsilon_{2}$ & $\varepsilon_{3}$ & $\varepsilon_{4}$ & $P_{\substack{\text { without } \\
R F B}}$ & $\varepsilon_{1}$ & $\varepsilon_{2}$ & $\varepsilon_{3}$ & $\varepsilon_{4}$ & $P_{R F B}$ \\
\hline Case 1 & 0.974 & 0.887 & 0.134 & 0.028 & 1.067 & 0.860 & 0.795 & 0.110 & 0.017 & 0.397 \\
\hline Case 2 & 1.087 & 0.968 & 0.211 & 0.032 & 1.275 & 0.900 & 0.822 & 0.151 & 0.018 & 0.411 \\
\hline Case 3 & 1.325 & 1.026 & 0.298 & 0.044 & 3.253 & 0.955 & 0.920 & 0.190 & 0.027 & 0.424 \\
\hline Case 4 & 1.184 & 1.323 & 0.223 & 0.066 & 0.771 & 0.964 & 0.965 & 0.153 & 0.041 & 0.520 \\
\hline Case 5 & 1.460 & 1.376 & 0.301 & 0.084 & 3.938 & 1.298 & 1.143 & 0.270 & 0.064 & 0.393 \\
\hline Case 6 & 0.925 & 0.876 & 0.149 & 0.094 & 1.262 & 0.811 & 0.800 & 0.137 & 0.070 & 0.437 \\
\hline Case 7 & 1.125 & 0.916 & 0.217 & 0.097 & 1.454 & 0.953 & 0.884 & 0.188 & 0.088 & 0.454 \\
\hline Case 8 & 1.324 & 1.026 & 0.325 & 0.100 & 3.498 & 0.963 & 0.964 & 0.263 & 0.090 & 0.441 \\
\hline Case 9 & 1.233 & 1.328 & 0.214 & 0.183 & 1.037 & 0.940 & 1.113 & 0.197 & 0.177 & 0.493 \\
\hline Case 10 & 1.375 & 1.346 & 0.342 & 0.197 & 3.266 & 1.203 & 1.161 & 0.295 & 0.182 & 0.494 \\
\hline
\end{tabular}

Table 5(a)CAI with no \& with RFB units $(K=1)$ form TATRIPS 
Ancillary Service Requirements Assessment Indices with the LFC in a Restructured Power Systems for RFB Unit by using Bacterial Foraging Optimization

\begin{tabular}{|l|l|l|l|l|l|l|l|l|l|l|}
\hline \multirow{2}{*}{ TATRIPS } & \multicolumn{3}{|c|}{ CAI based on control input deviations $\left(\Delta P_{c}\right)$} & \multicolumn{4}{|c|}{$\begin{array}{c}\text { CAI based on control input deviations } \\
\left(\Delta P_{c}\right) \text { with RFB unit (K=1) }\end{array}$} \\
\cline { 2 - 11 } & $\varepsilon_{5}$ & $\varepsilon_{6}$ & $\varepsilon_{7}$ & $\varepsilon_{8}$ & $\int P_{\text {without }}$ & $\varepsilon_{5}$ & $\varepsilon_{6}$ & $\varepsilon_{7}$ & $\varepsilon_{8}$ & $\int P_{R F B}$ \\
& & & & & & & & & & \\
\hline Case 11 & 1.133 & 1.516 & 0.340 & 0.297 & 1.102 & 1.000 & 1.241 & 0.300 & 0.238 & 0.497 \\
\hline Case 12 & 1.523 & 1.523 & 0.381 & 0.342 & 3.193 & 1.087 & 1.354 & 0.322 & 0.300 & 0.594 \\
\hline Case 13 & 1.344 & 1.624 & 0.430 & 0.495 & 1.893 & 1.003 & 1.428 & 0.384 & 0.423 & 0.568 \\
\hline Case 14 & 1.626 & 1.734 & 0.457 & 0.511 & 3.270 & 1.430 & 1.557 & 0.394 & 0.484 & 0.584 \\
\hline
\end{tabular}

Table 5(b)CAI with no \& with in RFB units (utilizes factors $K=0.75$ ) form TATRIPS

\begin{tabular}{|c|c|c|c|c|c|c|c|c|c|c|}
\hline \multirow[t]{2}{*}{ TATRIPS } & \multicolumn{5}{|c|}{$\begin{array}{l}\text { CAI based on control input deviations }\left(\Delta P_{c}\right) \\
\text { without RFB unit }(\mathrm{K}=0)\end{array}$} & \multicolumn{5}{|c|}{$\begin{array}{l}\text { CAI based on control input deviations } \\
\left(\Delta P_{c}\right) \text { with RFB unit }(\mathrm{K}=0.75)\end{array}$} \\
\hline & $\varepsilon_{5}$ & $\varepsilon_{6}$ & $\varepsilon_{7}$ & $\varepsilon_{8}$ & $P_{\text {without }}$ & $\varepsilon_{5}$ & $\varepsilon_{6}$ & $\varepsilon_{7}$ & $\varepsilon_{8}$ & $P_{R F B}$ \\
\hline Case 11 & 1.133 & 1.516 & 0.340 & 0.297 & 1.102 & 1.027 & 1.334 & 0.308 & 0.248 & 0.444 \\
\hline Case 12 & 1.523 & 1.523 & 0.381 & 0.342 & 3.193 & 1.106 & 1.413 & 0.323 & 0.307 & 0.522 \\
\hline Case 13 & 1.344 & 1.624 & 0.430 & 0.495 & 1.893 & 1.014 & 1.500 & 0.388 & 0.414 & 0.537 \\
\hline Case 14 & 1.626 & 1.734 & 0.457 & 0.511 & 3.270 & 1.441 & 1.607 & 0.400 & 0.488 & 0.544 \\
\hline
\end{tabular}

Table 5(c)CAI with no \&with RFB units $(K=0.5)$ form TATRIPS

\begin{tabular}{|c|c|c|c|c|c|c|c|c|c|c|}
\hline \multirow[t]{2}{*}{ TATRIPS } & \multicolumn{5}{|c|}{$\begin{array}{l}\text { CAI based on control input deviations }\left(\Delta P_{c}\right) \\
\text { without RFB unit }(\mathrm{K}=0)\end{array}$} & \multicolumn{5}{|c|}{$\begin{array}{l}\text { CAI based on control input deviation } \\
\left(\Delta P_{c}\right) \text { with RFB unit }(\mathrm{K}=0.5)\end{array}$} \\
\hline & $\varepsilon_{5}$ & $\varepsilon_{6}$ & $\varepsilon_{7}$ & $\varepsilon_{8}$ & $\int P_{\text {without }}$ & $\varepsilon_{5}$ & $\varepsilon_{6}$ & $\varepsilon_{7}$ & $\varepsilon_{8}$ & $P_{R F B}$ \\
\hline Case 11 & 1.133 & 1.516 & 0.340 & 0.297 & 1.102 & 1.053 & 1.324 & 0.318 & 0.251 & 0.384 \\
\hline Case 12 & 1.523 & 1.523 & 0.381 & 0.342 & 3.193 & 1.197 & 1.433 & 0.323 & 0.313 & 0.446 \\
\hline Case 13 & 1.344 & 1.624 & 0.430 & 0.495 & 1.893 & 1.086 & 1.544 & 0.400 & 0.427 & 0.324 \\
\hline Case 14 & 1.626 & 1.734 & 0.457 & 0.511 & 3.270 & 1.483 & 1.613 & 0.407 & 0.498 & 0.463 \\
\hline
\end{tabular}

Table 5(d)CAI with no \& with RFB units (utilization factor $K=0.25$ ) form TATRIPS

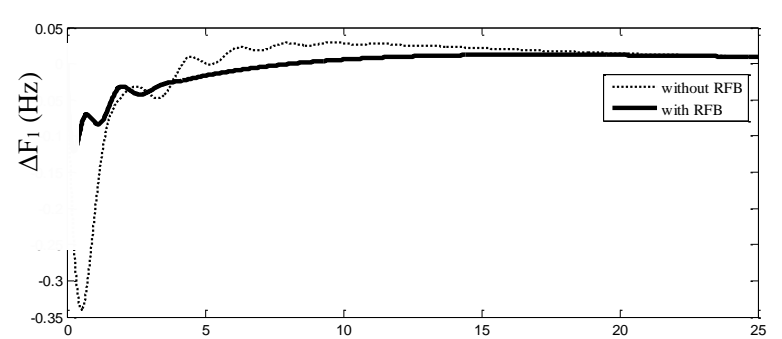

Figure.6 (a) $\Delta \mathrm{F}_{1}(\mathrm{~Hz})$ Vs Time (s') Time (s)

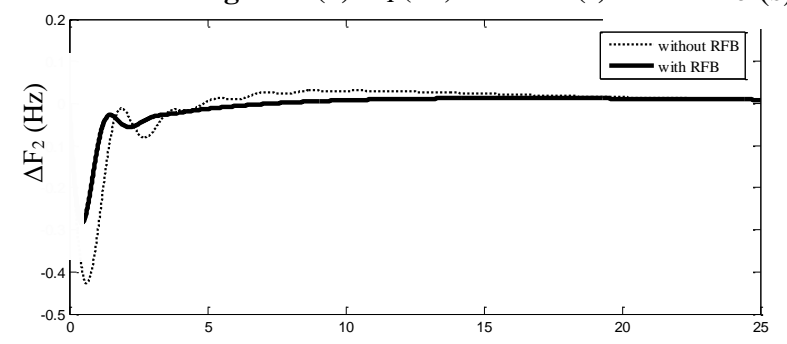

Figure.6(b) $\Delta \mathrm{F}_{2}(\mathrm{~Hz}) \mathrm{Vs}$ Time (s) Time (s)

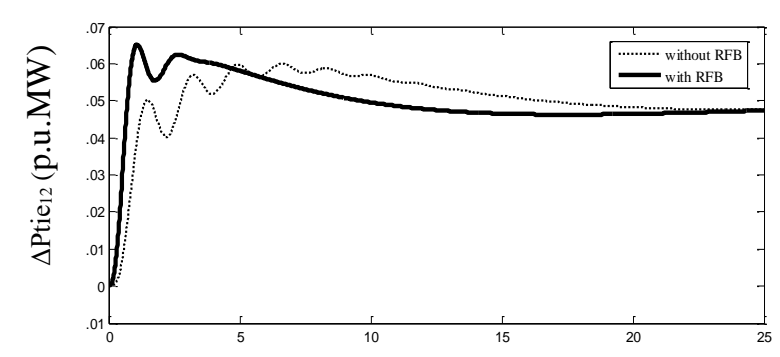

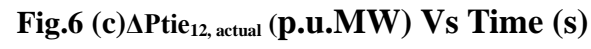

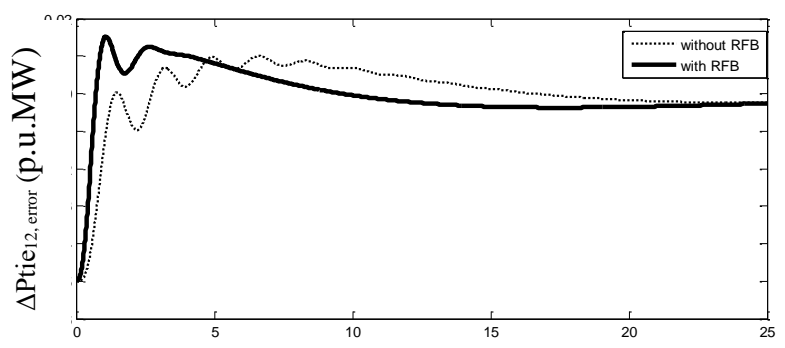

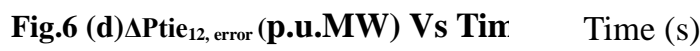




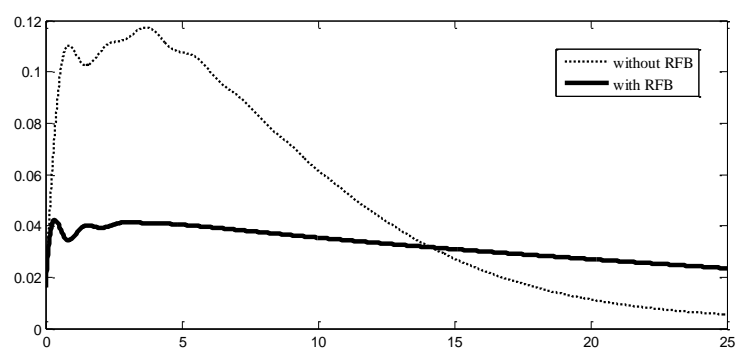

Fig.6 (e) $\Delta \mathrm{Pc}_{1}$ (p.u.MW)Vs Time (s)

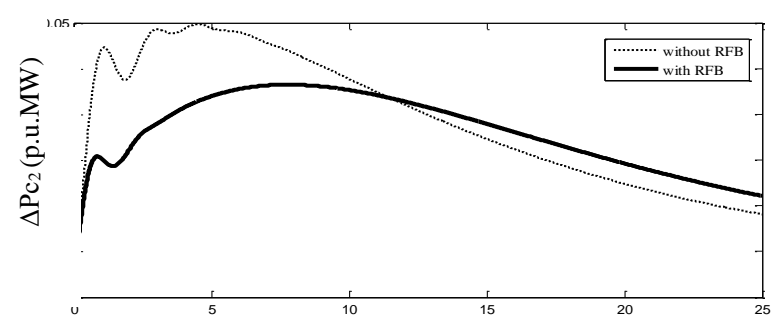

Fig.6 (f) $\Delta \mathrm{Pc}_{2}$ (p.u.MW) Vs Time (s)

Time (s)

Fig.6 Dynamic responses of the frequency deviations, tieline power deviations, and Control input deviations for TATRIPS in the restructure scenarios-2 (bilateralsbase transactions)

\section{CONCLUSIONS}

This paper proposes the implementation of assorted installation adjuvant service demand Assessment Indices (PSASRAI), which illustrates the need for adoption to minimize frequencies deviated, tideline power deviations during the two areas thermal heat interconnected restructured installation in a faster way to ensure efficient operation of the installation process. The PI controller's square calculation built the BFO equation to be manipulated and applied during a TATRIPS while not using the RFB method.This BFO equation was used to realize the maximum profit value parameters of the different combined management methods as it is easy to implement the BFO formula without additional device performance, with very shows potential resultin the ability to take advantage to the native optima. In addition, energy flowing controls is to RFB units was establish is to cost-effective be efficient in the complex load frequency management performance of the interconnected installation as opposed to that of the network and not the RFB units. In the simulation result is to be identifiesso as to the restoration induced calculates form the TATRIPS for RFB system indicate additional refined management for a more robust restoration of the machine quality responses of the facilities and to ensure improved installation adjuvant Services Requirements Assessments Indices (PSASRAI) intogive a smarter stability margins than that to the TATR.

\section{REFERENCES}

1. H.Shayeeghi, H.A.Shaayanfar\&A. Jaliili, "Load frequency regulate approaches: A state-of-the-art survey for the researcher", Energy Conveersion\&Maanagement, Vol. 50, Issue 2, pp. 344-353, 2009.

2. Mukta, Balwinder Singh Surjan, "Load-Frequency Control of Interrelated Power-System in Decontrolled Environment: A LiteratureReview", International Journal of Engineering\&Advanced: Vol. 2, Issue-3, pp. 435-441, 2013.

3. ElyasRaakhshani, "Theoretical viewpointsd on load-frequency control problematic in a decontrolled power-system", Energy Conversion\&Management, Vol. 51, No. 5, pp.1148 -1156, 2010.

4. V. Donde,\&I. A. Hiskens, "Simulation\&optimization in an AGCsystem after deregulation",IEEE Transactions on Power-Systems, Vol.16, No.3, pp.481-489, 2001.

5. Tan Wen, Zhang. "Decentralized load frequency regulate in decontrolled environments", Electrical Poweer\&Eneergy Systems, Vol.41, pp.16-26, 2012.

6. Bhatt .P, Roy.R, Ghoshal..SP, “Optimized multi-area AGC simulation in reorganized power-systems", Electrical Power\&Energy-Systems, Vol.32, pp.311 -322, 2010.

7. B.Paramasivam, "Optimized Load- Frequency Simulation in ReorganizedPower-System with Redox Flow Batteries andInterline Power-Flow Controller", International Journal of Electrical Power\&Energy Systems, Vol.50, pp 9-24, Feb 2013.

8. J.O.P.Rahi, Harish Kumar Thakur, Abhash Kumar Singh, Shashi Kant Gupta, "Ancillary Facilities in Reorganized Environment of Power structure", International Journal of Innovative Technology\&Research, Vol. 1, Issue No. 3, pp.218-225, 2013.

9. Hassan HaesAlhelou" Challenges\&Opportunities of Load- Frequency Control in Conservative, Modern\&Future Smart Power Systems: A Comprehensive Review",Energies 2018

10. K. Chandrasekar," Ancillary FacilityRequisiteValuation Indices for the Load-Frequency Control in a Reorganized Power-System with Redox Flow Batteries", J ElectrEng Technol.2016.

11. FerasAlshehriaVíctorGarcíaSuáreza,"Modelling\&evaluation of PEM hydrogen technologies for frequency ancillary facilities in future multienergy sustainable power systems",Heliyon, Volume 5, Issue 4, April 2019

12. Lakshmi DHANDAPANI, Peerfathima ABDULKAREEM," Two-area load frequency-control with redox flow battery using intellectual algorithms in a efficient scenario", Turkish Journal of Electrical Engineering \& Computer Sciences, (2018) 26: 330 - 346.APPENDIX A1 Data for TRPS

Rating of each area $=2000 \mathrm{MW}$, Base power $=2000 \mathrm{MVA}, \mathrm{f}^{\circ}=60 \mathrm{~Hz}, \mathrm{R}_{1}=$ $\mathrm{R}_{2}=\mathrm{R}_{3}=\mathrm{R}_{4}=2.4 \mathrm{~Hz} /$ p.u.MW, $\quad \mathrm{T}_{\mathrm{g} 1}=\mathrm{T}_{\mathrm{g} 2}=\mathrm{T}_{\mathrm{g} 3}=\mathrm{T}_{\mathrm{g} 4}=0.08 \mathrm{~s}, \mathrm{~T}_{\mathrm{r} 1}=$ $\mathrm{T}_{\mathrm{r} 2}=\mathrm{T}_{\mathrm{r} 1}=\mathrm{T}_{\mathrm{r} 2}=10 \mathrm{~s}, \mathrm{~T}_{\mathrm{t} 1}=\mathrm{T}_{\mathrm{t} 2}=\mathrm{T}_{\mathrm{t} 3}=\mathrm{T}_{\mathrm{t} 4}=0.3 \mathrm{~s}, \mathrm{~K}_{\mathrm{p} 1}=\mathrm{K}_{\mathrm{p} 2}=120 \mathrm{~Hz} /$ p.u.MW, $\mathrm{T}_{\mathrm{p} 1}=\mathrm{T}_{\mathrm{p} 2}=20 \mathrm{~s}, \beta_{1}=\beta_{2}=0.425$ p.u.MW $/ \mathrm{Hz}, \mathrm{K}_{\mathrm{r} 1}=\mathrm{K}_{\mathrm{r} 2}=\mathrm{K}_{\mathrm{r} 3}=\mathrm{K}_{\mathrm{r} 4}=0.5$, $2 \pi T_{12}=0.545$ p.u.MW $/ \mathrm{Hz}, \mathrm{a}_{12}=-1$.

A.2 Data for the RFB unit [14]

$\mathrm{T}_{\mathrm{RFB}}=0, \mathrm{~T}_{\mathrm{di}}=0, \mathrm{~T}_{\mathrm{ri}}=0$

\section{AUTHOR PROFILE}

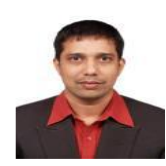

Dr. ND. Sridhar, Associate Professor, Department of Electrical Engineering, Annamalai University, Tamilnadu, India. An active researcher, He is published large number of paper in national\&international journals. His research interests are in Power System stability, optimization techniques, distributed generation, Power system restructuring\&Deregulation. Email id: sridarnd1@gmail.com 